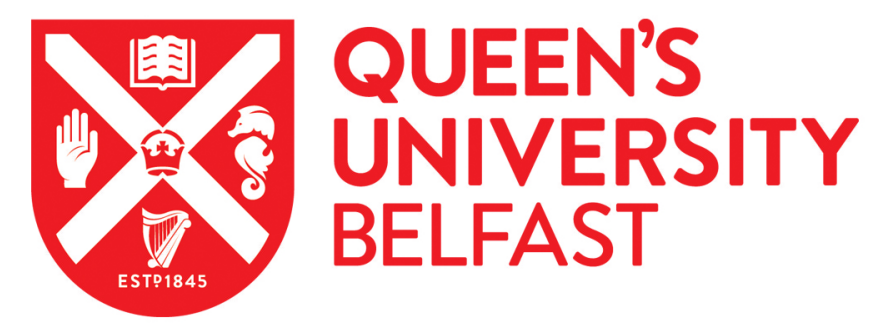

\title{
Trastuzumab cardiotoxicity in HER2-positive breast cancer patients in tertiary health care center, sultanate of Oman
}

Abd Alghafar, D., Younos, I., Al Baimani, K., Al-Salhi, D., Al-Riyami, A., Rizvi, S., \& Buckley, N. E. (2020). Trastuzumab cardiotoxicity in HER2-positive breast cancer patients in tertiary health care center, sultanate of Oman. Journal of Oncology Pharmacy Practice. https://doi.org/10.1177/1078155220919888

Published in:

Journal of Oncology Pharmacy Practice

Document Version:

Peer reviewed version

Queen's University Belfast - Research Portal:

Link to publication record in Queen's University Belfast Research Portal

Publisher rights

(C) 2020 The Authors.

This work is made available online in accordance with the publisher's policies. Please refer to any applicable terms of use of the publisher.

\section{General rights}

Copyright for the publications made accessible via the Queen's University Belfast Research Portal is retained by the author(s) and / or other copyright owners and it is a condition of accessing these publications that users recognise and abide by the legal requirements associated with these rights.

Take down policy

The Research Portal is Queen's institutional repository that provides access to Queen's research output. Every effort has been made to ensure that content in the Research Portal does not infringe any person's rights, or applicable UK laws. If you discover content in the Research Portal that you believe breaches copyright or violates any law, please contact openaccess@qub.ac.uk. 


\section{Journal of Oncology Pharmacy Practice}

\section{Trastuzumab Cardiotoxicity in HER2-Positive Breast Cancer Patients in Tertiary Health Care Center, Sultanate of Oman}

\begin{tabular}{|r|l|}
\hline Journal: & Journal of Oncology Pharmacy Practice \\
\hline Manuscript ID & JOPP-19-0474.R1 \\
\hline Kanuscript Type: & Original Article \\
\hline Keywords: & Trastuzumab, Cardiotoxicity, HER2, Breast Cancer, chemotherapy \\
\hline & $\begin{array}{l}\text { Trastuzumab, a monoclonal antibody, targeting the human epidermal } \\
\text { growth factor receptor 2 (HER2), is used to treat breast cancer in } \\
\text { patients harboring amplification of the HER2 locus. Cardiotoxicity is a } \\
\text { common side effect of trastuzumab that leads to discontinuation of } \\
\text { treatment in a significant proportion of cancer patients. } \\
\text { In our retrospective study, we evaluate the prevalence and identify the } \\
\text { risk factors for cardiotoxicity associated with trastuzumab in HER2- } \\
\text { positive breast cancer patients attending to Sultan Qaboos University } \\
\text { Hospital between 10/2012 and 10/2017. Using patient records, we } \\
\text { collected patients' characteristics (age, menopausal status, lymph nodal } \\
\text { status, distant metastasis at presentation, grade of tumor, comorbidities } \\
\text { (diabetes mellitus, hypertension, coronary artery disease diseases)), } \\
\text { chemotherapy received and total dose of trastuzumab as well as } \\
\text { cardiotoxicity (including timing). Cardiotoxicity was defined based on the } \\
\text { ejection fraction dropping by 10\% of the original value or a drop in the } \\
\text { ejection fraction below the normal value. Among the 146 patients } \\
\text { included in the study, 35 showed trastuzumab-induced cardiotoxicity } \\
\text { (TIC) (24\%). Twenty-nine (83\%) of those patients stopped trastuzumab } \\
\text { temporarily. None of the cardiac risk factors, such as history of coronary } \\
\text { artery disease, hypertension and diabetes, altered the risk of TIC. } \\
\text { Previous anthracyclines therapy exposure increased the risk of TIC } \\
\text { significantly (p=0.009). None of the other covariates influenced the } \\
\text { incidence of TIC, which can be related to the relatively small sample size. } \\
\text { Further studies are warranted to establish ways to predict, prevent, and } \\
\text { treat TIC to provide patients with maximal therapeutic benefit. }\end{array}$ \\
\hline Abstract \\
\hline
\end{tabular}

\section{SCHOLARONE Manuscripts}




\section{Abstract}

Trastuzumab, a monoclonal antibody targeting the human epidermal growth factor receptor 2 (HER2), is used to treat breast cancers harboring amplification of the HER2 locus. Cardiotoxicity is a common side effect of Trastuzumab that leads to discontinuation of treatment in a significant proportion of cancer patients.

In our retrospective study, we evaluate the prevalence and identify the risk factors for cardiotoxicity associated with Trastuzumab in HER2-positive breast cancer patients attending to Sultan Qaboos University Hospital between 10/2012 and 10/2017. Using patient records, we collected patients' characteristics (age, menopausal status, lymph nodal status, distant metastasis at presentation, grade of tumor, comorbidities (diabetes mellitus, hypertension, coronary artery disease diseases)), chemotherapy received and total dose of Trastuzumab as well as cardiotoxicity (including timing). Cardiotoxicity was defined based on the ejection fraction dropping by $10 \%$ of the original value or a drop in the ejection fraction below the normal value. Among the 146 patients included in the study, 35 showed Trastuzumab-induced cardiotoxicity (TIC) $(24 \%)$. Twenty-nine (83\%) of those patients stopped Trastuzumab temporarily. Risk of TIC was not altered by common cardiac risk factors such as history of coronary artery disease, hypertension and diabetes. Previous anthracyclines therapy exposure increased the risk of TIC significantly $(p=0.009)$. None of the other covariates influenced the incidence of TIC, which may be related to the relatively small sample size. Further studies are warranted to establish ways to predict, prevent, and treat TIC to provide patients with maximal therapeutic benefit.

\section{Keywords}

Trastuzumab, Cardiotoxicity, HER2, Breast Cancer, Chemotherapy 


\section{List of Abbreviations}

5-FU: 5-Fluorouracil

AC: Doxorubicin and Cyclophosphamide

ACEIs: Angiotensin-converting enzyme inhibitors

ARBs: Angiotensin Receptor Blockers

BBs: Beta Blockers

BC: Breast Cancer

BMI: Body Mass Index

CAD: Coronary Artery Disease

CDRs: Complementary determining regions

CoMHS: College of Medicine and Health Sciences

CMF: Cyclophosphamide, Methotrexate and 5-Fluorouracil

CMR: Cardiac magnetic resonance imaging.

DM: Diabetes Mellitus

ECHO: Echocardiogram

ER: Estrogen Receptor

FEC: 5-Fluorouracil plus Epirubicin plus Cyclophosphamide

HER2: Human Epidermal growth factor Receptor 2

HF: Heart Failure

LVEF: Left ventricular Ejection Fraction

mAb: Monoclonal Antibody

MBC: Metastatic Breast Cancer

MUGA: Multigated Radionuclide Angiography

muMAb: Murine Monoclonal Antibody

OCP: Oral Contraceptives

PI3K: Phosphoinositide 3-kinase

PR: Progesterone Receptor

SQUH; Sultan Qaboos University Hospital

TIC: Trastuzumab-Induced Cardiotoxicity 


\section{Introduction}

Understanding the biology of breast cancer (BC) has helped to identify the human epidermal growth factor receptor 2 (HER2), encoded by the HER2 gene which is amplified and overexpressed in $15-20 \%$ of breast cancers and associated with tumor proliferation, migration, and differentiation through its involvement in the activation of the PI3K/Akt and Ras/-Raf/MEK/MAPK pathways. (1) HER2 amplification is also associated with incomplete resistance to hormonal therapy, improved response to anthracycline-containing chemotherapy regimens and poor response to Cyclophosphamide, Methotrexate and 5-Fluorouracil (CMF) chemotherapy combination. (2)

In late 1990s, a humanized monoclonal antibody targeting the extracellular domain of HER2, Trastuzumab, was approved for treatment of patients with HER2 positive metastatic BC. ${ }^{(3-5)}$ This humanized form of muMAb-4D5 was engineered by grafting the antigen binding loops of the hypervariable CDRs to a human $\operatorname{IgG}_{1}$ framework. (6) Trastuzumab was investigated in numerous preclinical studies in HER2 positive $\mathrm{BC}$ cell lines and xenograft models in immunodeficient mice, revealing anti-tumour activity as a monotherapy and in combination with several chemotherapeutic agents involving, thiotepa, cisplatin, paclitaxel, vinblastine, doxorubicin, methotrexate and etoposide. ${ }^{(7)}$ 
The mechanism of action of Trastuzumab in $\mathrm{BC}$ treatment is is complex and multifactorial and not completely understood. ${ }^{(8)}$ Proposed mechanisms include PI3K pathway inhibition, ${ }^{(9)}$ promotion of an immune-mediated response, ${ }^{(10-12)}$ inhibition of HER2-ECD cleavage, (13-15) promotion of HER2-receptor downregulation, (16,17) induction of cell cycle arrest through post-translational upregulation of $\mathrm{p} 27^{\mathrm{kip} 1}{ }^{(\mathbf{1 8})}$ and inhibition of angiogenesis $\mathbf{( 1 9 , 2 0 )}$.

As preclinical Trastuzumab studies suggested that HER2 played an essential role in the developing embryonic heart and is important for maintaining cardiac function in the adult heart, (21) there were considerable concerns regarding its cardiotoxicity in early clinical trials (22). It is believed that Trastuzumab-induced cardiotoxicity (TIC) is the result of a 'dual-hit' mechanism; it directly inhibits antiapoptotic pathways and upregulates angiotensin II, a potent vasoconstrictor, leading to an increase in the reactive oxygen species production and inhibition of neuregulin signaling, an important role in the regulation of cardiac structure and function. (23)

TIC ranges from asymptomatic left ventricular dysfunction to chronic heart failure (HF). ${ }^{(24)}$ Although the primary risk for TIC is reportedly the combination with anthracycline-based chemotherapy, ${ }^{(25,26)}$ a number of other TIC risk factors have been described. These include treatment duration, $(24,27,28)$ heavy alcohol consumption during treatment and history of diabetes mellitus (DM) ${ }^{(29,30)}$ or cardiovascular disease ${ }^{(25,29,31,32)}$. None of these risk factors can precisely predict occurrence and it is 
important to note that patients with these risk factors were excluded from the majority of clinical trials.

Although TIC has become better understood (given increased experience with this agent) and risk factors identification, appropriate monitoring and treatment procedures are well-established, TIC incidence and associated risk factors have not yet been studied in Oman. This knowledge would improve predictability and contribute to a better population-based selection for Trastuzumab-containing regimens in HER2 positive $\mathrm{BC}$ in the Omani population.

In this study, we evaluate the incidence and risk factors related to TIC in patients with HER2 positive BC within different Trastuzumab treatment settings. We also determine and assess treatments used for alleviating TIC and rates of cardiac function recovery. 


\section{Methods}

\section{Study Design and Settings}

This is a single center retrospective cohort study. Using an institutional medical records database, all early and advanced $\mathrm{BC}$ patients treated with Trastuzumab were identified at Adult Medical Oncology Unit, SQUH, Muscat, Oman, from 1 October 2012 to 1 October 2017. 146 patients were identified and were eligible for the study.

\section{Inclusion Criteria}

- HER2 positive BC patients.

- Adult age group including both women.

- High quality baseline 2D-echocardiogram (ECHO) and LVEF $\geq 50 \%$.

- Treatment with Trastuzumab as monotherapy or Trastuzumab-containing regimen.

- Available information on Trastuzumab dosing and clinical outcomes.

\section{Exclusion Criteria}

- Patients with previous cancer before their first diagnosis of BC.

- Life expectancy $\leq 12$ weeks.

- Age $\leq 18$ or $\geq 75$ years.

- Patients with incomplete data. 


\section{Ethical Approval}

Ethical approval (\# 1661) was granted by the Medical Research Ethics Committee (MERC) at SQU, CoMHS before starting the study. Confidentiality was strictly maintained throughout the study.

\section{Data Collection}

The following data were extracted retrospectively from electronic medical records for each patient: age, gender, tumor characteristics, body mass index, $\mathrm{BC}$ side, use of radiation therapy, menopausal state, Trastuzumab schedule, Trastuzumab cumulative dose, estrogen and progesterone receptor status, cardiac risk factors (DM, hypertension, hypercholesterolemia and ischemic heart diseases), use of antihypertensive and statins medications, previous chemotherapy received, concurrent chemotherapy, concurrent pertuzumab, concurrent hormonal treatment, timing of cardiotoxicity, treatment used to alleviate cardiotoxicity and EF recovery rates after cardiotoxicity. In addition, we collected data regarding presentation with HF symptoms or asymptomatic and re-challenge rate.

Cardiac risk factors included hypertension (defined as blood pressure $>140 / 90 \mathrm{~mm}$ $\mathrm{Hg}$ maintained over time or use of antihypertensive drugs), dyslipidemia (defined as total plasmatic cholesterol $>5.2 \mathrm{mmol} / \mathrm{L}$ or use of lipid-lowering medications), DM (diagnosed as fasting serum glucose $\geq 7.0 \mathrm{mmol} / \mathrm{L}$ 2-h post challenge serum glucose $\geq 11.1 \mathrm{mmol} / \mathrm{L}$ or use of hypoglycemic medications). All patients underwent a 
comprehensive baseline cardiac examination and $\mathrm{ECHO}$ as part of their routine prechemotherapy evaluation. Both evaluations were repeated before starting Trastuzumab (baseline) and almost every 3 months thereafter for the duration of therapy.

\section{Trastuzumab Regimens}

Patients received Trastuzumab dose of $8 \mathrm{mg} / \mathrm{kg}$ of body weight administered as a 90minute intravenous infusion as loading dose, followed by maintenance doses of 6 $\mathrm{mg} / \mathrm{kg}$ given every 3 weeks. Patients that completed the adjuvant treatment without interruption received 18 doses and the total length was approximately 1 year. Trastuzumab was administered sequential to anthracyclines and patients with metastatic breast cancer (MBC) continue anti HER2 beyond progression.

\section{Trastuzumab-induced Cardiotoxicity (TIC) Definition and Monitoring}

TIC was defined according to the criteria followed by Herceptin Adjuvant (HERA) clinical trial as symptomatic (e.g., HF and/or dyspnea, and/or referral to a cardiologist for confirmation) or asymptomatic (e.g., decline in LVEF $>10 \%$ from baseline or LVEF $<50 \%{ }^{(33)}$. Cardiac monitoring to determine LVEF was performed every 3 months using serial MUGA or an ECHO at the discretion of the treating medical oncologist. 


\section{Statistical Analysis}

Descriptive statistics were used to describe the number of patients experiencing a LVEF reduction. Significance of differences between mean values was evaluated using Independent Student's two-sample $t$-test, (SPSS 23.0, Inc., Chicago, IL). Correlation analyses were undertaken using chi-square analysis. Data were presented as mean \pm SEM. Significance was assumed at $p$ value of $\leq 0.05$. 


\section{Results}

The characteristics of the patients included in the study are summarized in Table 1. The study population included 146 patients (range 29-74 years, mean age of $48.10 \pm 10$ years and mean BMI of 29.44) who received Trastuzumab in a neoadjuvent, adjuvant, pseudoadjuvent (chemotherapy given as adjuvant after resection of locoregional recurrence) and/or palliative settings. As shown in Table 2, there was a low prevalence of preexisting DM, dyslipidemia, CAD and hypertension. All patients were New York Heart Association (NYHA) functional class I at baseline. All patients were diagnosed with BC with HER 2 amplification, fulfilling the American College of Physicians (ACP)/American Society of Clinical Oncology (ASCO) criteria for treatment with anti HER2 agent, mainly Trastuzumab.

In this study, cardiotoxicity was more common in patients receiving beta blockers (BBs) (Figure 1) but was less in patients receiving statins and equivocal in patients receiving and not receiving ACEIs (Figure 1). In relation to menopausal status, cardiotoxicity was more common in patients with pre-menopausal status (Table 2). In addition, proportion of patients who developed cardiotoxicity was equivocal in patients with metastatic $\mathrm{BC}$ and with those without metastatic diseases (Table 2). Ptients with right-sided BC developed less cardiotoxicity compared to those with cancer on the left side (Table 2). Additionally, cardiotoxicity was high in patients with $\mathrm{PR}+$ disease compared to those with PR- or ER $+/ \mathrm{PR}+$ disease (Table 
2). The majority of patients received anthracycline-based chemotherapy regimens containing either doxorubicin or epirubicin. Cardiotoxicity was significantly higher in patients receiving doxorubicin compared to those who do not receive anthracyclines or epirubicin or both and there was significant association between doxorubicin administration and TIC $(p=0.009)$ (Table 2). Concurrent Taxanes and Pertuzumab administration was not significantly associated with cardiotoxicity (Table 2 and 4). A non-significant trend was observed for the association between radiotherapy and cardiotoxicity with lower cardiotoxicity in patients not receiving radiotherapy (Table 2). While a pre-existing history of hypertension was more common in those patients who developed TIC (Table 1), a pre-existing history of dyslipidemia, CAD and DM was less common in those patients who developed TIC (Table 1).

For the population with preserved LVEF, all patients in the adjuvant setting received a total of 12 months of Trastuzumab treatment while patients in the palliative setting received Trastuzumab indefinitely unless other anti-HER2 agents were given. For the population who developed LV systolic dysfunction, the mean duration of treatment with Trastuzumab was $3 \pm 4.5$ months. The mean LVEF for the total population was $63.9 \pm 5.3$ on ECHO. In patients who developed symptomatic cardiomyopathy ( $\mathrm{n}=15,42.85 \%)$, symptoms were exertional dyspnea, orthopnea, fatigability, dyspnea, palpitation and chest pain with 1 patient died from Trastuzumab-induced HF. TIC was also diagnosed in asymptomatic patients $(n=20$, 
$57.14 \%$ ) based on changes in LVEF levels. Both groups received appropriate HF medications including ACEIs/ARBs (100\%) and BBs (70\%) (Table 2).

Of the 35 patients who developed cardiotoxicity, 1 patient died due to disease progression, 5 patients completed their Trastuzumab treatment without interruption as they were at the end of the therapy and 29 patients temporary discontinued Trastuzumab therapy. Following the temporary discontinuation of Trastuzumab, all 29 patients underwent serial MUGA and ECHO at the time of diagnosis of cardiac dysfunction as well as 3 and 6 months post-diagnosis. Most of patients who developed cardiotoxicity recovered after treatment $(n=22,62.85 \%)$ with mean LVEF $54.79 \%$, and 13 patients were re-challenged with the same dose of Trastuzumab with a mean re-challenge time of 5.4 months. (Table 3) 


\section{Discussion}

Although Trastuzumab is not known to cause the classical toxicities associated with chemotherapy or other targeted therapy medications, one of the major concerns is the occurrence of cardiac dysfunction. Therefore, this study was designed with the aim of identifying the potential risk factors for cardiac toxicity associated with Trastuzumab treatment among Omani patients with HER2 positive BC.

This study contributes to the growing volume of literature reporting higher incidences of TIC compared to that reported within randomized controlled trials (RCTs) that led to Trastuzumab approval. In the HERA and NSABP-31 RCTs symptomatic TIC was reported as $2.1 \%$ and $5 \%$ respectively. ${ }^{(34)}$ Moreover, TIC incidence of $23.97 \%$ at tertiary hospital in Oman is similar to results in other retrospective studies from various countries that reported $16 \%, 21 \%$ and $24 \%$ in USA, Israel and Canada respectively. ${ }^{(35-37)}$ However, the TIC incidence in this study was lower compared to studies in Brazil reporting 33-53\% ${ }^{(38-39)}$.

One hypothesis to explain these differences between the "real world" and RCT incidence lies in the strict inclusion and wide exclusion criteria applied to RCTs. Contraindications to study entry in RCTs include patients with previously documented cardiac disease, adequate baseline hepatic, renal, and bone marrow function. Additionally, it is possible that the heterogeneity in the definition of asymptomatic TIC contributes to the differences between RCT and observational 
studies. In the HERA RCT, decrease in LVEF was defined as a decline of $\geq 10 \%$ from baseline to LVEF $<50 \%$ at any time ${ }^{(40)}$, while in the BCIRG 006 RCT, LVEF was defined as a relative reduction from baseline of more than $10 \%$ at the last evaluation (26). Observational studies also vary in the definition of asymptomatic TIC from LVEF absolute reduction of $\geq 16-10 \%$ from baseline and drops in LVEF $<50-55 \%$. $(38,41)$

In our study, a definition of asymptomatic TIC as a decline in LVEF $\geq 10 \%$ from baseline or LVEF $<50 \%$ was used based on HERA RCT ${ }^{(40)}$. The median time to development of TIC from Trastuzumab initiation in adjuvant setting was 8.5 months and 36 months in palliative setting.

In the current study, known cardiac risk factors were not associated with increased risk of TIC. This differs from the results of a a retrospective analysis of 218 metastatic BC patients who received Trastuzumab for at least 1 year from 1998 to 2003 where higher rates of TIC was associated with a history of $\mathrm{DM}^{(\mathbf{4 2})}$. However, a prospective cohort study by Matos et al. where 92 patients were studied for possible risk factors associated with TIC, DM or dyslipidemia did not appear to be associated with increased cardiomyopathy risk. ${ }^{(43)}$ The difference in the results among these studies may be attributed to small samples size.

Patients in our study who used BBs for hypertension and CAD treatment showed significant association with TIC. This association could be a confounding to a preexisting heart disease rather than a true association. In fact, this observation was 
not supported by other previous studies. On the contrary, there are other studies supporting the idea that BBs show favorable effects on preventing cardiotoxicity associated with Trastuzumab. (44) Hypertension, the most extensively studied comorbidity in this patients' population, is a generally accepted risk factor and its importance was confirmed in several studies. (31) Nevertheless, the results are not uniform and there are studies that, like this study, could not demonstrate its predictive role. ${ }^{(45)}$

Additionally, we did not find that CAD was an important predictive factor of TIC, which is in contrary to the results obtained from a study performed by Xue and colleagues where they found that the risk of cardiotoxicity was more strongly associated with the history of CAD among patients treated with Trastuzumab. (46) However, there are other studies that could not confirm its predictive value such as the one performed by Tarantini and colleagues. ${ }^{(41)}$

While our patients' age and BMI were comparable to reported adjuvant studies (31,45,47), patients' age was not found as an important predictive factor in this study, which is in contrary to the results of two North American prospective randomized clinical studies ${ }^{(31,45)}$. On the other hand, there are studies that could not confirm its predictive value, among them the HERA study as well as "real-world" studies. (47-48) In the HERA study, ${ }^{(45)}$ BMI was found to be important risk factor. However, this was not demonstrated or not extensively studied in another studies ${ }^{(31)}$. In this study, BMI did not emerge as important risk factor. 
Due to the proximity of the heart in the chest wall, there is a hypothesis of the association between left-sided breast cancer with radiation and the development of TIC. Data from the NCCTG N9831 RCT investigated concomitant Trastuzumab and radiotherapy in 908 patients and found no significant differences between radiated and non-radiated groups. ${ }^{\left({ }^{(9)}\right)}$ A study by Cao et al. ${ }^{(50)}$ reported that left-sided radiation with increased low-dose volume and mean heart dose was associated with reversible low-grade cardiac toxicity. In this study, there was no significant association between radiotherapy, left side breast tumor and TIC.

As treatment plans for $\mathrm{BC}$ patients are generally complex, with more than 1 modality, it is often hard to dissect the cardiotoxic effect of each individual regimen. These treatments may interact with each other and have added effect to the cardiovascular system. Indeed, this study found that previous anthracycline use is a significant risk factor for developing TIC $(p=0.009)$ which is similar to the results obtained from a meta-analysis conducted by Jawa et al. $2016^{(\mathbf{5 1 - 5 3 )}}$.

For docetaxel containing regimen, a study conducted by Shimoyam and colleagues illustrated that docetaxel is a cardiotoxic agent that induces cardiac contractile dysfunction. ${ }^{(54)}$ However, the results from Pegram et al. 2007 found that docetaxel/Trastuzumab containing regimen could offer clinical efficacy with a low risk of cardiac dysfunction. (4) In this study, docetaxel is trending towards a significant association with TIC $(p=0.085)$. this may be attributed to its cardiotoxic effect as its mechanism of action is primarily related to its ability to increase 
microtubule assembly and to stabilize microtubules by preventing their depolymerization, thus disrupting normal cell division. It has been shown that increased microtubule density, for which microtubule stabilization is one potential mechanism, causes contractile dysfunction in cardiac hypertrophy. (54)

Studies showed that TIC seems to be reversible when Trastuzumab is withdrawn. ${ }^{(55,56)}$ Twenty-nine $(82.85 \%)$ patients who discontinued the treatment in our study recovered from the cardiac events (Table 3). Another study showed a lower percentage $(9.4 \%)$ of recovery. ${ }^{(54)}$ However, both studies lack a more rigorous investigation of the long-term effects of this anticancer therapy in order to verify TIC reversibility. Treatment discontinuation and/or management of cardiovascular side effects with cardio protective agents such as ACEIs or diuretics are recommended strategies to revert TIC and all 35 patients within this cohort received cardiovascular medications after the development of TIC. However, there are clinical studies showed that the discontinuation of Trastuzumab alone is able to restore cardiac function and/or prevent cardiac events in patients with a decrease in LVEF lower than $40 \%$. (42) This finding suggests that there is a need to combine efforts between oncologists and cardiologists to determine which patient that developed TIC actually require the cardiovascular medication.

This study has several limitations associated with its retrospective nature. Given the small sample size, there were limitations in statistical power to perform further exploratory analyses. There were limitations by the quality of information 
available from the electronic medical records and other potential variables such as physical inactivity. Cardiac biomarkers such as Troponin-I and B-type natriuretic peptide, were not collected as they are not part of the standard-of-care. LVEF assessments were also conducted with MUGA or ECHO, adding inter-study and inter-operator variability across different tests. Additionally, this study was limited by the short follow-up time and therefore cannot determine the long-term incidence of TIC. 


\section{Conclusions}

To our knowledge, this investigation is the first retrospective study conducted in Oman to assess the incidence of TIC, the rate of Trastuzumab discontinuation and to investigate possible factors associated with TIC in clinical practice. This study showed a moderate incidence of TIC among HER2 positive breast cancer patients (24\%) and that there is a need of a closer cardiac monitoring to prevent cardiac complications in this population.

Although 5 patients finished the treatment without interruption, 29 patients discontinued the therapy temporary, suggesting that it is important to stimulate collaboration between cardiologists and oncologists to outweigh the risks of this anticancer therapy and to identify patients that need cardiovascular medication after developing TIC. In addition, previous BBs and anthracyclines use were significantly associated with TIC in this population. However, no cardiovascular risk factors were independently associated with TIC. Larger studies should be conducted in order to confirm which specific factors are associated with the development of TIC to early identify potential cardiovascular injury and to establish strategies to prevent TIC among this population. 


\section{Funding Acknowledgements}

This research received no specific grant from any funding agency in the public, commercial, or not-for-profit sectors.

\section{Declaration of conflicting interests}

The Authors declare that there is no conflict of interest. 


\section{Tables}

Table 1:

Sociodemographic and clinical characteristics of the studied population

\begin{tabular}{|c|c|}
\hline Total patients (146) & n (\%) \\
\hline $\begin{array}{c}\text { Age group (years) } \\
<35 \\
35-49 \\
50-59 \\
>60\end{array}$ & $\begin{array}{ll}15 & (10.27 \%) \\
72 & (49.31 \%) \\
32 & (21.91 \%) \\
27 & (18.49 \%)\end{array}$ \\
\hline $\begin{array}{ll}\text { BMI } & \\
& <20 \\
& 20-24 \\
& 25-29 \\
& >30\end{array}$ & $\begin{array}{ll}6 & (4.10 \%) \\
29 & (19.86 \%) \\
55 & (37.67 \%) \\
56 & (38.35 \%)\end{array}$ \\
\hline $\begin{array}{l}\text { Cardiac risks } \\
\text { Hypertension } \\
\text { Diabetes mellitus } \\
\text { Dyslipidemia } \\
\text { CAD } \\
\text { Cardiovascular medications } \\
\text { Radiotherapy } \\
\end{array}$ & $\begin{array}{l}68(46.58 \%) \\
34(23.29 \%) \\
32(21.92 \%) \\
10(6.85 \%) \\
68(46.58 \%) \\
120(82.19 \%) \\
\end{array}$ \\
\hline $\begin{array}{l}\text { Tumor location } \\
\text { Left } \\
\text { Right } \\
\text { Bilateral } \\
\end{array}$ & $\begin{array}{ll}80 & (54.79 \%) \\
66 & (44.52 \%) \\
0 & \\
\end{array}$ \\
\hline $\begin{array}{l}\text { Menopausal Status } \\
\text { Pre-menopausal } \\
\text { Post-menopausal } \\
\end{array}$ & $\begin{array}{ll}91 & (62.32 \%) \\
55 & (37.67 \%) \\
\end{array}$ \\
\hline $\begin{array}{c}\text { Hormone receptor status } \\
\text { ER }-\mathbf{P R}- \\
\text { ER }+ \text { PR - } \\
\text { PR }+ \text { ER - } \\
\text { ER }+ \text { PR + } \\
\end{array}$ & $\begin{array}{ll}60 & (41.09 \%) \\
10 & (6.8 \%) \\
2 & (1.36 \%) \\
74 & (50.68 \%) \\
\end{array}$ \\
\hline $\begin{array}{ll}\text { Stage } & \\
& \text { I } \\
\text { II } \\
\text { III } \\
\text { IV }\end{array}$ & $\begin{array}{ll}7 & (4.79 \%) \\
39 & (26.71 \%) \\
63 & (43.15 \%) \\
37 & (25.34 \%)\end{array}$ \\
\hline $\begin{array}{c}\text { Chemotherapy regimen } \\
\text { AC } \\
\text { FEC } \\
\text { Others }\end{array}$ & $\begin{array}{ll}88 & (60.27 \%) \\
20 & (13.69 \%) \\
37 & (26.04 \%)\end{array}$ \\
\hline Radiotherapy & $120(82.19 \%)$ \\
\hline Family history of cancer & $13(8.9 \%)$ \\
\hline $\begin{array}{c}\text { Cardiovascular medication } \\
\text { Beta blocker } \\
\text { ACE inhibitors } \\
\end{array}$ & $\begin{array}{ll}35 & (23.97 \%) \\
29 & (19.86 \%) \\
\end{array}$ \\
\hline
\end{tabular}




\begin{tabular}{|c|cl|}
\hline Statins & 32 & $(21.91 \%)$ \\
\hline Anthracycline-based chemotherapy & & \\
Treatment without anthracyclines & 48 & $(32.88 \%)$ \\
Epirubicin & 10 & $(6.8 \%)$ \\
Doxorubicin & 78 & $(53.42 \%)$ \\
Both Doxorubicin and Epirubicin & 10 & $(6.8 \%)$ \\
\hline
\end{tabular}

BMI: Body Mass Index, ER: Estrogen Receptor, PR: Progesterone Receptor, AC: Doxorubicin plus Cyclophosphamide, FEC: 5-Fluorouracil plus Epirubicin plus Cyclophosphamide. 
Table 2:

Factors associated with Trastuzumab-induced cardiotoxicity

\begin{tabular}{|c|c|c|c|}
\hline \multicolumn{4}{|c|}{ TIC } \\
\hline & Yes $(n=35)$ & No $(n=111)$ & $p$ value \\
\hline $\begin{array}{c}\text { Age group (years) } \\
<35 \\
\quad 35-49 \\
50-59 \\
>60\end{array}$ & $\begin{array}{ll}3 & (20 \%) \\
21 & (29.2 \%) \\
8 & (25 \%) \\
3 & (11.1 \%)\end{array}$ & $\begin{array}{l}12(80 \%) \\
51(70.8 \%) \\
24(75 \%) \\
24(88.9 \%)\end{array}$ & $\begin{array}{l}1.000 \\
0.176 \\
1.000 \\
0.132\end{array}$ \\
\hline $\begin{array}{ll}\text { BMI } & \\
& <20 \\
& 20-24 \\
& 25-29 \\
& >30\end{array}$ & $\begin{array}{l}1(16.7 \%) \\
6(20 \%) \\
13(24.5 \%) \\
15(26.3 \%)\end{array}$ & $\begin{array}{l}5(83.3 \%) \\
24(80 \%) \\
40(75.5 \%) \\
42(73.7 \%)\end{array}$ & $\begin{array}{l}1.000 \\
0.639 \\
1.000 \\
0.692\end{array}$ \\
\hline $\begin{array}{l}\text { Cardiac risks } \\
\text { Hypertension } \\
\text { Diabetes mellitus } \\
\text { Dyslipidemia } \\
\text { CAD } \\
\text { Cardiovascular medications } \\
\text { Radiotherapy } \\
\end{array}$ & $\begin{array}{ll}19 & (27.9 \%) \\
6 & (17.6 \%) \\
6 & (18.8 \%) \\
2 & (20.0 \%) \\
19 & (27.9 \%) \\
30 & (25.0 \%) \\
\end{array}$ & $\begin{array}{l}49(72.1 \%) \\
28(82.4 \%) \\
26(81.3 \%) \\
8(80.0 \%) \\
49(72.1 \%) \\
90(75.0 \%) \\
\end{array}$ & $\begin{array}{c}0.334 \\
0.369 \\
0.492 \\
1.000 \\
0.334 \\
0.620 \\
\end{array}$ \\
\hline $\begin{array}{c}\text { Chemotherapy } \\
\text { Docetaxel } \\
\text { Taxanes } \\
\text { Pertuzumab }\end{array}$ & $\begin{array}{l}32(27.1 \%) \\
33(25.2 \%) \\
5 \quad(19.2 \%)\end{array}$ & $\begin{array}{l}86(72.9 \%) \\
98(74.8 \%) \\
21(80.8 \%)\end{array}$ & $\begin{array}{l}0.085 \\
0.523 \\
0.620\end{array}$ \\
\hline $\begin{array}{l}\text { Anthracyclines } \\
\text { Treatment without anthracyclines } \\
\text { Doxorubicin } \\
\text { Epirubicin } \\
\text { Both Doxorubicin and Epirubicin }\end{array}$ & $\begin{array}{ll}5 & (10.4 \%) \\
27 & (34.6 \%) \\
1 & (10.0 \%) \\
2 & (20.0 \%)\end{array}$ & $\begin{array}{ll}43 & (89.6 \%) \\
51 & (65.4 \%) \\
9 & (90.0 \%) \\
8 & (80.0 \%)\end{array}$ & $0.009 * * *$ \\
\hline Metastasis & $13(24.1 \%)$ & $41(75.9 \%)$ & 1.000 \\
\hline $\begin{array}{r}\text { Breast Side } \\
\text { Left } \\
\text { Right } \\
\end{array}$ & $\begin{array}{l}23(28.7 \%) \\
12(18.2 \%)\end{array}$ & $\begin{array}{l}57(71.3 \%) \\
54(81.8 \%)\end{array}$ & 0.173 \\
\hline $\begin{array}{l}\text { Hormone receptor status } \\
\text { ER }- \text { PR - } \\
\text { ER + PR - } \\
\text { PR + ER- } \\
\text { ER + PR + }\end{array}$ & $\begin{array}{ll}15 & (25.0 \%) \\
1 & (10.0 \%) \\
1 & (50.0 \%) \\
18 & (24.3 \%)\end{array}$ & $\begin{array}{ll}45 & (75.0 \%) \\
9 & (90.0 \%) \\
1 & (50.0 \%) \\
56 & (75.7 \%)\end{array}$ & 0.581 \\
\hline $\begin{array}{c}\text { Menopausal status } \\
\text { Pre-menopausal } \\
\text { Post-menopausal }\end{array}$ & $\begin{array}{l}26(28.6 \%) \\
9(16.4 \%)\end{array}$ & $\begin{array}{l}65(71.4 \%) \\
46(83.6 \%)\end{array}$ & 0.112 \\
\hline OCP & $8 \quad(28.6 \%)$ & $20(71.4 \%)$ & 0.623 \\
\hline
\end{tabular}

TIC: Trastuzumab-Induced Cardiotoxicity, BMI: Body Mass Index, AC: Doxorubicin plus Cyclophosphamide, FEC: 5-fluorouracil plus Epirubicin plus Cyclophosphamide, OCP: Oral Contraceptive, ER: Estrogen Receptor, PR: Progesterone Receptor, CAD: Coronary Artery Disease. 
Table 3:

Incidence of Trastuzumab-induced cardiotoxicity and treatment discontinuation

\begin{tabular}{|l|l|l|l|l|l|}
\hline & $\mathbf{n}(\mathbf{\%})$ & $\begin{array}{c}\text { Presence of } \\
\text { HF } \\
\text { Symptoms }\end{array}$ & $\begin{array}{c}\text { Permanent } \\
\text { Treatment } \\
\text { Discontinuation }\end{array}$ & $\begin{array}{c}\text { Temporary } \\
\text { Treatment } \\
\text { Discontinuation }\end{array}$ & $\begin{array}{c}\text { Treatment } \\
\text { Without } \\
\text { Discontinuation }\end{array}$ \\
\hline TIC & $35(23.97)$ & $15(42.85 \%)$ & $1(2.85 \%)$ & $29(82.85 \%)$ & $5(14.28 \%)$ \\
\hline LVEF decline by $\geq \mathbf{1 0} \%$ & $33(94.28)$ & $15(42.85 \%)$ & $1(2.85 \%)$ & $27(77.14 \%)$ & $5(14.28 \%)$ \\
\hline LVEF decline to $<\mathbf{5 0} \%$ & $22(62.85)$ & $13(37.14 \%)$ & $1(2.85 \%)$ & $19(54.28 \%)$ & $2(5.71 \%)$ \\
\hline
\end{tabular}

TIC: Trastuzumab-Induced Cardiotoxicity, LVEF: Left Ventricular Ejection Fraction, HF: Heart Failure 
Table 4:

Trastuzumab-induced cardiotoxicity associated with concurrent chemotherapeutic medications.

Number of patients and their percent within the treatment group are included.

\begin{tabular}{|c|c|c|c|}
\hline & & \multicolumn{2}{|c|}{ Cardiotoxicity } \\
\hline & & No & Yes \\
\hline \multirow{2}{*}{ Docetaxel } & No & $25(89.3 \%)$ & $3(10.7 \%)$ \\
\hline & Yes & $86(72.9 \%)$ & $32(27.1 \%)$ \\
\hline \multirow{2}{*}{ Paclitaxel } & No & $98(75.4 \%)$ & $32(24.6 \%)$ \\
\hline & Yes & $13(81.3 \%)$ & $3(18.8 \%)$ \\
\hline \multirow{2}{*}{ Nab paclitaxel } & No & $101(75.9 \%)$ & $32(24.1 \%)$ \\
\hline & Yes & $10(76.9 \%)$ & $3(23.1 \%)$ \\
\hline \multirow{2}{*}{ Tamoxifen } & No & $51(76.1 \%)$ & $16(23.9 \%)$ \\
\hline & Yes & $60(75.9 \%)$ & $19(24.1 \%)$ \\
\hline \multirow{2}{*}{ Letrozole } & No & $101(74.8 \%)$ & $34(25.2 \%)$ \\
\hline & Yes & $10(90.9 \%)$ & $1(9.1 \%)$ \\
\hline \multirow{2}{*}{ Exemestane } & No & $109(75.7 \%)$ & $35(24.3 \%)$ \\
\hline & Yes & $2(100.0 \%)$ & $0(0.0 \%)$ \\
\hline \multirow{2}{*}{ Eribulin } & No & $109(75.7 \%)$ & $35(24.3 \%)$ \\
\hline & Yes & $2(100.0 \%)$ & $0(0.0 \%)$ \\
\hline \multirow{2}{*}{ Vinorelbine } & No & $102(76.1 \%)$ & $32(23.9 \%)$ \\
\hline & Yes & $9(75.0 \%)$ & $3(25.0 \%)$ \\
\hline \multirow{2}{*}{ Cyclophosphamide } & No & $109(75.7 \%)$ & $35(24.3 \%)$ \\
\hline & Yes & $2(100.0 \%)$ & $0(0.0 \%)$ \\
\hline \multirow{2}{*}{ Liposomal Doxorubicin } & No & $111(76.6 \%)$ & $34(23.4 \%)$ \\
\hline & Yes & $0(0.0 \%)$ & $1(100.0 \%)$ \\
\hline \multirow{2}{*}{ Capecitabine } & No & $109(76.8 \%)$ & $33(23.2 \%)$ \\
\hline & Yes & $2(50.0 \%)$ & $2(50.0 \%)$ \\
\hline \multirow{2}{*}{ Lapitinib } & No & $108(76.6 \%)$ & $33(23.4 \%)$ \\
\hline & Yes & $3(60.0 \%)$ & $2(40.0 \%)$ \\
\hline \multirow{2}{*}{ Pertuzumab } & No & $90(75.0 \%)$ & $30(25.0 \%)$ \\
\hline & Yes & $21(80.8 \%)$ & $5(19.2 \%)$ \\
\hline \multirow{2}{*}{ Carboplatin } & No & $87(73.7 \%)$ & $31(26.3 \%)$ \\
\hline & Yes & $24(85.7 \%)$ & $4(14.3 \%)$ \\
\hline \multirow{2}{*}{ Gemcitabine } & No & $95(74.8 \%)$ & $32(25.2 \%)$ \\
\hline & Yes & $16(84.2 \%)$ & $3(15.8 \%)$ \\
\hline
\end{tabular}




\section{Figures}

\section{Figure 1:}

Trastuzumab-induced cardiotoxicity associated with Beta Blockers, statins and ACE inhibitors

Number of patients is included on each bar.

ACE inhibitors: angiotensin converting enzyme inhibitors

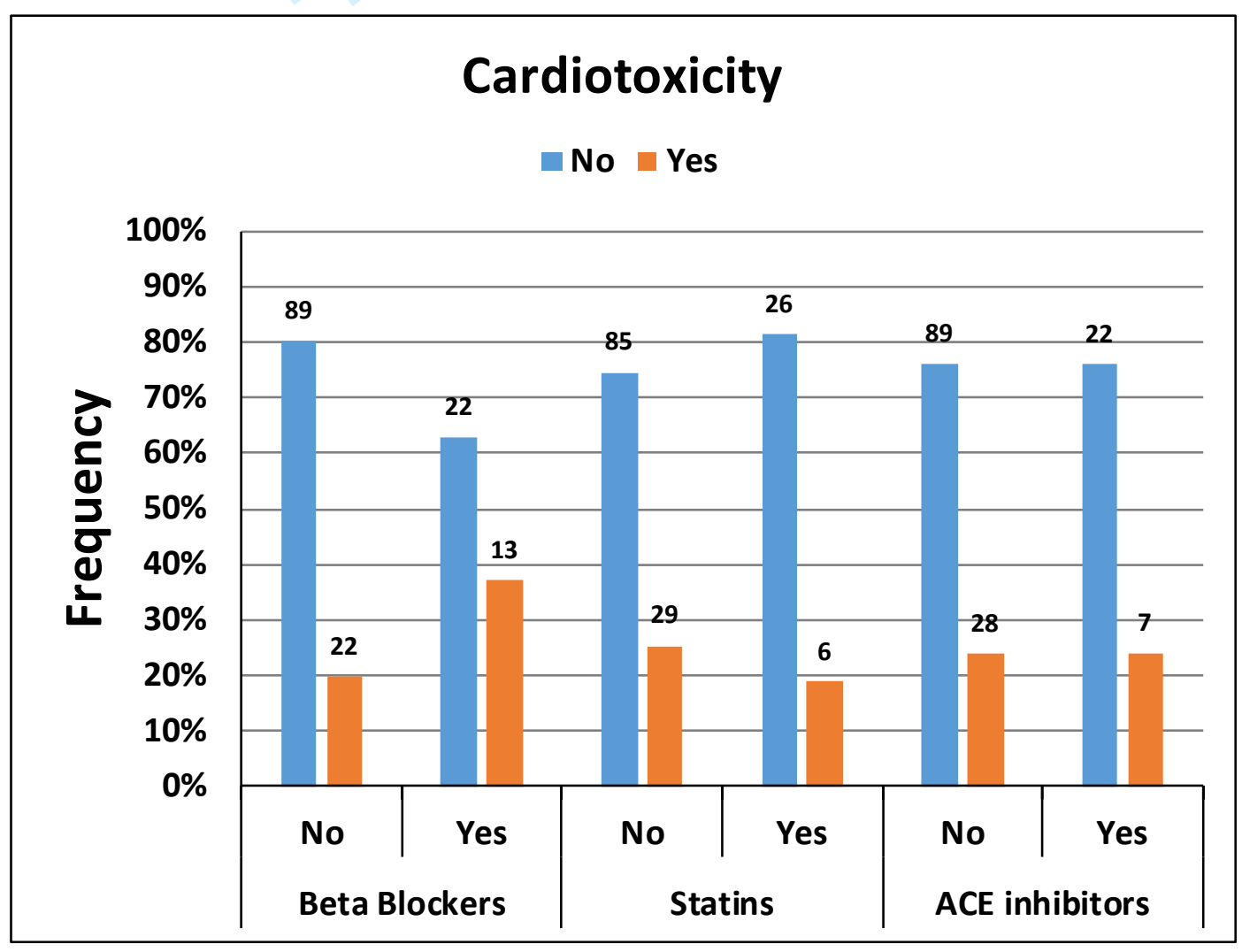




\section{Figure 2:}

\section{Trastuzumab-induced cardiotoxicity associated with different treatment settings}

Number of patients is included on each bar.

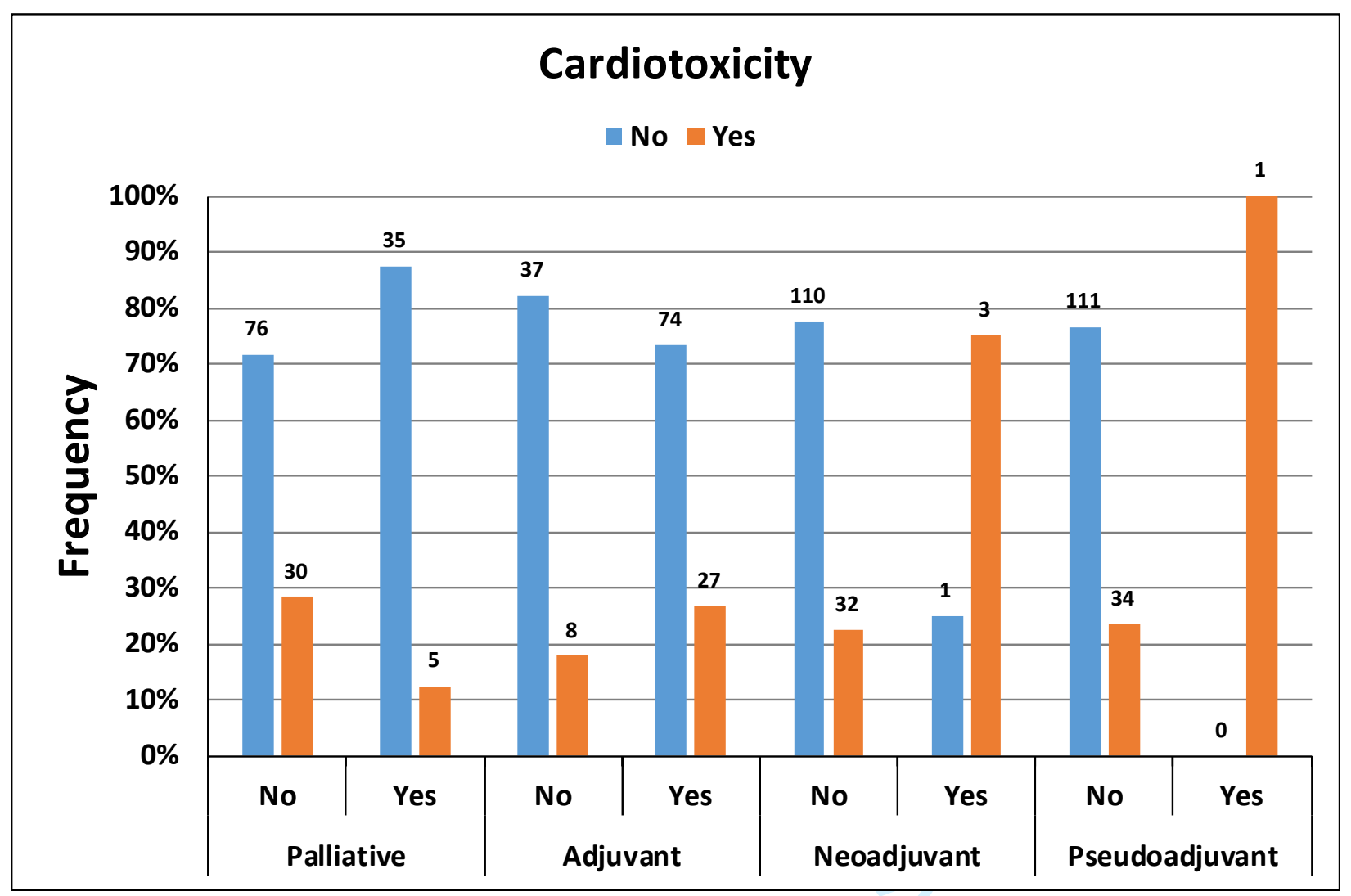




\section{References}

1. Ross JS and Fletcher JA. HER-2/neu (c-erb-B2) gene and protein in breast cancer. Am. J. Clin. Pathol. 1999 Jul; 112(1 Suppl 1): S53-S67.

2. Jin Zhang and Yan Liu. HER2 over-expression and response to different chemotherapy regimens in breast cancer. J. Zhejiang. Univ. Sci. B. 2008 Jan; 9(1): $5-9$.

3. Carter P, Presta L, Gorman C, Ridgway J, Henner D, Wong W, et al. Humanization of an anti-p185 HER2 antibody for human cancer therapy. Proc Natl Acad Sci USA. 1992; 89:4285-9.

4. Pietras R, Pegram M, Finn R, Maneval D, Slamon D. Remission of human breast cancer xenografts on therapy with humanized monoclonal antibody to HER-2 receptor and DNA-reactive drugs. Oncogene. .1998 Oct 29; 17:2235-2249.

5. Shepard HM, Jin P, Slamon DJ, Pirot Z, Maneval DC. Herceptin. In: Chernajovsky Y., Nissim A. (eds) Therapeutic Antibodies. Handbook of Experimental Pharmacology 2008; 181:183-219.

6. Baselga J, Tripathy D, Mendelsohn J, Baughman S, Benz CC, Dantis L, et al. Phase II study of weekly intravenous recombinant humanized anti-p185HER2 monoclonal antibody in patients with HER2/neu-overexpressing metastatic breast cancer. J Clin Oncol. 1996; 14:737-744.

7. Cobleigh MA, Vogel CL, Tripathy D, Robert NJ, Scholl S, Fehrenbacher L, et al. Multinational study of the efficacy and safety of humanized anti-HER2 monoclonal antibody in women who have HER2-overexpressing metastatic breast cancer that has progressed after chemotherapy for metastatic disease. J Clin Oncol. 1999; 17: 2639-2648.

8. Gennari R, Menard S, Fagnoni F, Ponchio L, Scelsi M, Tagliabue E, et al. Pilot study of the mechanism of action of preoperative Trastuzumab in patients with primary operable breast tumors overexpressing HER2. Clin Cancer Res. 2004; 10:5650-5655.

9. Fresno Vara J, Casado E, de Castro J, Cejas P, Belda-Iniesta C, González-Barón M. PI3K/Akt signalling pathway and cancer. Cancer Treat Rev. 2004; 30:193-204. 
10.Plosker GL, Keam SJ. (2006) Trastuzumab: a review of its use in the management of HER2- positive metastatic and early-stage breast cancer. Drugs. 2006; 66:449475.

11. Valabrega G, Montemurro F, Aglietta M. Trastuzumab: mechanism of action, resistance and future perspectives in HER2-overexpressing breast cancer. Ann Oncol. 2007 Jan; 18 (6):977- 984.

12.Beano A, Signorino E, Evangelista A, Brusa D, Mistrangelo M, Polimeni M, et al. Correlation between NK function and response to Trastuzumab in metastatic breast cancer patients. J Trans Med. 2008; 6:25-34.

13. Molina MA1, Codony-Servat J, Albanell J, Rojo F, Arribas J, Baselga J. Trastuzumab (Herceptin), a humanized anti-Her2 receptor monoclonal antibody, inhibits basal and activated Her2 ectodomain cleavage in breast cancer cells. Cancer Res. 2001 Jun 15;61(12):4744-9.

14.Esteva FJ, Cheli CD, Fritsche H, Fornier M, Slamon D, Thiel RP, et al. Clinical utility of serum HER2/neu in monitoring and prediction of progression-free survival in metastatic breast cancer patients treated with Trastuzumab-based therapies. Breast Cancer Res. 2005; 7: R436-443.

15.Fornier M, Seidman A, Schwartz M, Ghani F, Thiel R, Norton L, et al. Serum HER2 extracellular domain in metastatic breast cancer patients treated with weekly Trastuzumab and paclitaxel: association with HER2 status by immunohistochemistry and fluorescence in situ hybridization and with response rate. Ann Oncol. 2005; 16:234-239.

16. Sarup JC, Johnson RM, King KL, Fendly BM, Lipari MT, Napier MA, et al. Characterization of an anti-p185HER2 monoclonal antibody that stimulates receptor function and inhibits tumor cell growth. Growth Regul. 1991 Jun; 1:72 82.

17. Cuello M, Ettenberg SA, Clark AS, Keane MM, Posner RH, Nau MM, et al. Downregulation of the erbB-2 receptor by Trastuzumab (herceptin) enhances tumor necrosis factor-related apoptosis-inducing ligand-mediated apoptosis in breast and ovarian cancer cell lines that overexpress erbB 2. Cancer Res. 2001; 61:4892-4900. 
18.Xiao-Feng Le, Francois-Xavier Claret, Amy Lammayot, Ling Tian, Deepa Deshpande, Ruth LaPushin, et al. The Role of Cyclin-dependent Kinase Inhibitor p2 $7^{\text {Kip1 }}$ in Anti-HER2 Antibody-induced G1 Cell Cycle Arrest and Tumor Growth InhibitionJ. Biol. Chem. 2003; 278: 23441- 23450.

19.Izumi Y, Xu L, di Tomaso E, Fukumura D, Jain RK. Tumour biology: Herceptin acts as an anti-angiogenic cocktail. Nature 2002 Mar 21; 416(6878):279-80.

20.Klos KS, Zhou X, Lee S, Zhang L, Yang W, Nagata Y, et al. Combined Trastuzumab and paclitaxel treatment better inhibits ErbB-2-mediated angiogenesis in breast carcinoma through a more effective inhibition of Akt than either treatment alone. Cancer. 2003 Oct 1; 98:1377-1385.

21.Crone SA, Zhao YY, Fan L, Gu Y, Minamisawa S, Liu Y, et al. ErbB2 is essential in the prevention of dilated cardiomyopathy. Nat Med. 2002; 8:459-465

22. Slamon DJ, Leyland-Jones B, Shak S, Fuchs H, Paton V, Bajamonde A et al. (2001) Use of chemotherapy plus a monoclonal antibody against HER2 for metastatic breast cancer that overexpresses HER2. N. Engl. J. Med. 2001 Mar; 344:783-792.

23.Zeglinski M, Ludke A, Jassal DS, Singal PK. Trastuzumab-induced cardiac dysfunction: A 'dual-hit'. Exp. Clin. Cardiol. 2011 Fall; 16(3):70-4.

24.Moja L, Tagliabue L, Balduzzi S, Parmelli E, Pistotti V, Guarneri V et al. Trastuzumab containing regimens for early breast cancer. Cochrane Database Syst Rev. 2012; Apr 18; (4):CD006243.

25.Seidman A, Hudis C, Pierri MK, Shak S, Paton V, Ashby M, et al. Cardiac dysfunction in the Trastuzumab clinical trials experience. J. Clin. Oncol. 2002 March 1; 20:2319-2326.

26. Slamon D, Eiermann W, Robert N, Pienkowski T, Martin M, Press M et al. Adjuvant Trastuzumab in HER2-positive breast cancer. N. Engl. J. Med. 2011 Oct; 6; 365(14):1273-83.

27.Buzdar AU, Valero V, Ibrahim NK, Francis D, Broglio KR, Theriault RL, et al. Neoadjuvant therapy with paclitaxel followed by 5-fluorouracil, epirubicin, and cyclophosphamide chemotherapy and concurrent Trastuzumab in human epidermal growth factor receptor 2-positive operable breast cancer: an update of 
the initial randomized study population and data of additional patients treated with the same regimen. Clin Cancer Res. 2007 Jan 1;13(1):228-33.

28. Joensuu H, Kellokumpu-Lehtinen PL, Bono P, Alanko T, Kataja V, Asola R, et al. Adjuvant docetaxel or vinorelbine with or without Trastuzumab for breast cancer. N. Engl. J. Med. 2006 Feb 23; 354(8):809-20.

29.Serrano C., Cortés J., De Mattos-Arruda L., Bellet M., Gómez P., Saura C., et al. Trastuzumab-related cardiotoxicity in the elderly: a role for cardiovascular risk factors. Ann. Oncol. 2012 Apr; 23: 897-902

30.Lemieux J, Diorio C, Côté MA, Provencher L, Barabé F, Jacob S, et al. . Alcohol and HER2 polymorphisms as risk factor for cardiotoxicity in breast cancer treated with Trastuzumab. Anticancer Res. 2013 Jun; 33(6):2569-76.

31.Perez EA, Suman VJ, Davidson NE, Sledge GW, Kaufman PA, et al. Cardiac safety analysis of doxorubicin and cyclophosphamide followed by paclitaxel with or without Trastuzumab in the North Central Cancer Treatment Group N9831 adjuvant breast cancer trial. J. Clin. Oncol. 2008 Mar 10; 26(8):1231-8.

32.Cochet A., Quilichini G., Dygai-Cochet I., Touzery C., Toubeau M., BerrioloRiedinger A., et al. Baseline diastolic dysfunction as a predictive factor of Trastuzumab-mediated cardiotoxicity after adjuvant anthracycline therapy in breast cancer. Breast Cancer Res Treat. 2011; 130: 845-854

33. Chien AJ, Rugo HS. The cardiac safety of Trastuzumab in the treatment of breast cancer. Expert Opin Drug Saf. 2010; (2):335-46.

34.Sengupta PP, Northfelt DW, Gentile F, Zamorano JL and Khandheria BK. Trastuzumab-induced cardiotoxicity: heart failure at the crossroads. Mayo Clin. Proc. 2008 Feb; 83(2):197-203.

35. Anthony F. Yu, Nandini U. Yadav, Anne A. Eaton, Betty Y. Lung, Howard T. Thaler, Jennifer E. Liu, et al. Continuous Trastuzumab Therapy in Breast Cancer Patients with Asymptomatic Left Ventricular Dysfunction. Oncologist. 2015; 20(10):1105-1110.

36.Fried G, Regev T, Moskovitz M. Trastuzumab-related cardiac events in the treatment of early breast cancer. Breast Cancer Res Treat. 2013; Nov;142(1):1-7 
37. Wadhwa D, Fallah-Rad N, Grenier D, Krahn M, Fang T, Ahmadie R, Walker JR, et al.. Trastuzumab mediated cardiotoxicity in the setting of adjuvant chemotherapy for breast cancer: a retrospective study. Breast Cancer Res Treat. 2009 Sep;117(2):357-64.

38. Grazziotin Show all authors LR, Picon PD. Observational study of Trastuzumabrelated cardiotoxicity in early and metastatic breast cancer. J. Oncol Pharm Pract. 2017 Jun;23(4):264-272.

39. Ayres LR, de Almeida Campos MS, de Oliveira Gozzo T, Martinez EZ, Ungari AQ, de Andrade JM, et al. Trastuzumab induced cardiotoxicity in HER2 positive breast cancer patients attended in a tertiary hospital. Int J Clin Pharm. 2015; $37: 365-372$.

40.Piccart-Gebhart MJ, Procter M, Leyland-Jones B, Goldhirsch A, Untch M, et al. Trastuzumab after adjuvant chemotherapy in HER2-positive breast cancer. N Engl J Med. 2005 Oct 20;353(16):1659-72.

41.Tarantini L, Cioffi G, Gori S, Tuccia F, Boccardi L, Bovelli D, et al. Trastuzumab Adjuvant Chemotherapy and Cardiotoxicity in Real-World Women with Breast Cancer. J Card Fail. 2012 Feb; 18(2):113-9.

42.Valentina Guarneri, Daniel J. Lenihan, Vicente Valero, Jean-Bernard Durand, Kristine Broglio, Kenneth R. Hess, et al. Long-Term Cardiac Tolerability of Trastuzumab in Metastatic Breast Cancer: The M.D. Anderson Cancer Center Experience. J Clin Oncol. 2006 Sep 1;24(25):4107-15. Epub 2006 Aug 14. Erratum in: J Clin Oncol. 2008 May 10;26(14): 2421.

43. Matos E, Jug B, Blagus R, Zakotnik B, et al. A Prospective Cohort Study on Cardiotoxicity of Adjuvant Trastuzumab Therapy in Breast Cancer Patients. Arq. Bras. Cardiol. 2016 Jul;107(1):40-7.

44.Wittayanukorn S, Qian J, Johnson BS, Hansen RA (2017) Cardiotoxicity in targeted therapy for breast cancer: A study of the FDA adverse event reporting system (FAERS). J Oncol Pharm Pract. 2017 Mar;23(2):93-102.

45.Tan-Chiu E, Yothers G, Romond E, Geyer CE Jr, Ewer M, Keefe D, et al. Assessment of cardiac dysfunction in a randomized trial comparing doxorubicin and cyclophosphamide followed by paclitaxel, with or without Trastuzumab as adjuvant therapy in node-positive, human epidermal growth factor receptor 2- 
overexpressing breast cancer: NSABP B-31. J Clin Oncol. 2005 Nov 1; 23(31):7811-9.

46.Xue J, Jiang Z, Qi F, Lv S, Zhang S, Wang T, et al. Risk of Trastuzumab-Related Cardiotoxicity in Early Breast Cancer Patients: A Prospective Observational Study. J. Breast Cancer. 2014 Dec; 17(4):363-9.

47.Procter M, Suter TM, de Azambuja E, Dafni U, van Dooren V, Muehlbauer S, et al. Longer-term assessment of Trastuzumab-related cardiac adverse events in the Herceptin Adjuvant (HERA) trial. J Clin Oncol. 2010 Jul 20; 28(21):3422-8.

48.Piotrowski G, Gawor R, Bourge RC, Stasiak A, Potemski P, Gawor Z, et al. Heart remodeling induced by adjuvant Trastuzumab-containing chemotherapy for breast cancer overexpressing human epidermal growth factor receptor type 2: A prospective study. Pharmacol. Res. 2013 Dec; 78:41-8.

49.Halyard Y Michele, Thomas M. Pisansky, Amylou C. Dueck, Vera Suman, Lori Pierce, Larry Solin, et al.. Radiotherapy and Adjuvant Trastuzumab in Operable Breast Cancer: Tolerability and Adverse Event Data from the NCCTG Phase III Trial N9831. J. Clin. Oncol. 2009; 27(16): 2638-2644.

50.Cao L., Hu WG, Kirova YM, Yang ZZ, Cai G, Yu XL, et al. Potential impact of cardiac dose-volume on acute cardiac toxicity following concurrent Trastuzumab and radiotherapy. Cancer Radiother. 2014; Mar; 18(2):119-24.

51.Jawa Z, Perez RM, Garlie L, Singh M, Qamar R, Khandheria BK, et al. Risk factors of Trastuzumab- induced cardiotoxicity in breast cancer. Medicine (Baltimore). 2016 Nov; 95(44): e5195.

52.Mohan N, Jiang J, Dokmanovic M, Wu WJ. Trastuzumab-mediated cardiotoxicity: current understanding, challenges, and frontiers. Antib Ther. 2018;1(1):13-17.

53. Yu AF, Singh JC, Wang R, Liu JE, Eaton A, Oeffinger KC, et al. Cardiac Safety of Dual Anti-HER2 Therapy in the Neoadjuvant Setting for Treatment of HER2Positive Breast Cancer. Oncologist. 2017 Jun;22(6):642-647.

54. Shimoyama M., Murata Y., Sumi K., Hamazoe R. and Komuro I. Docetaxel induced cardiotoxicity. Heart 2001; 86(2): 219. 
55.Ewer MS, Vooletich MT, Durand JB, Woods ML, Davis JR, Valero V, et al. Reversibility of Trastuzumab-related cardiotoxicity: new insights based on clinical course and response to medical treatment. J. Clin Oncol. 2005; 23:7820-6.

56. Darryl P. Leong, Tammy Cosman, Muhammad M. Alhussein, Nidhi Kumar Tyagi, Sarah Karampatos, Carly C. Barron, et al. Safety of Continuing Trastuzumab Despite Mild Cardiotoxicity: A Phase I Trial. JACC: CardioOncology 2019 Sept 1; 1(1): 1-10.

57.Guglin M, Hartlage G, Reynolds C, Chen R, Patel V.. (2009). TrastuzumabInduced Cardiomyopathy: Not as Benign as it Looks? A Retrospective Study. J Card Fail. 2009 Oct;15(8):651-657. 